\title{
Adakah isu dan perlukah solusi gender in leadership?
}

\author{
Onny Setyawati \\ Jurusan Teknik Elektro, Fakultas TeknikUniversitas Brawijaya \\ Korespondensi Penulis: osetyawati@ub.ac.id
}

\begin{abstract}
Abstrak: Gender study tidak sekedar memberi nilai tambahpengetahuan pada keilmuan (rekayasa atau sains) tertentu, akan tetapi juga merupakan entitas karena kurikulum pada perguruan tinggi dibangun menurut nilai budaya dan social, bukan hanya berdasarkan metode danproses belajar/mengajar. Pengamatan pada studi kasus berikut fokus pada pengajar di jurusan Teknik Elektro. Terdapat kurang dari $20 \%$ dosen wanita di jurusan tersebut, namun sekitar $90 \%$ dari mereka memiliki posisi strategis pengambil keputusan. Oleh karena itu saat ini dapat dinyatakan bahwa isu gender bukanlah hal yang kritis. meskipun demikian lokakarya atau pelatihan terkait gender study tetap diperlukan, agar fenomena di bidang rekayasa ini tetap berkesinambungan.
\end{abstract}

Kata Kunci: Isu Gender, Pemimpin Wanita, Dosen Wanita Di Bidang Teknik

Abstract: Gender study provides not only adding value toknowledges in engineering or sciences, but also a substantial entity, since the curricula in higher educationare built according to cultural and social values. The subjects are not only based on teaching / learning methodsand processes. An observation in the following case studywas focused on lecturers in the Electrical Engineering department. There are less than $20 \%$ of female lecturers in the department, however, around $90 \%$ of these numbershave strategic decision-making positions (as leaders). Therefore, at this point it can be stated that gender issuesare not critical in this field. Nevertheless, workshops and/or training programs related to gender study/issues are still required thus this phenomenon of increasing number of women leaders in the engineering field continues.

Keyword: Gender issue, women leadership, female as lecturers inengineering fields

Article History:

Received : 2021-01-24

Revised : 2021-02-19

Accepted : 2021-03-17

\section{PENDAHULUAN}

Gender leadership dalam STEM telah dijabarkan oleh (McCullough, 2011), yang menyatakan bahwa jumlah women leadership di bidang engineering kurang dari 3\% sedangkan dibidang MIPA (Matematika dan IPA) sekitar 5,5\% para wanita yang memimpin department atau jurusan, menurut data dariasosiasi American Universities. McCullough menyebutkan sejumlah penyebabnya, antara lain adalah budaya yang jarang menjadi fokus bahasan, dibandingkan dengan solusi mentoring. Selain itu disebutkan pula, jika menjadi leader, wanita diharapkan memiliki gaya kepemimpinan yang berbeda,seperti tidak memakai riasan, menggunakan celana panjang,dan tidak menjadikan kehidupan sosial atau family sebagai kewajiban utama. Namun disebutkan pula bahwa sangat kurangnya data representatif juga menjadi sebab, dan karena durasi pimpinan jurusan hanya 5 hingga 6 tahun saja, oleh karena itu, tidak dapat diputuskan apakah wanita menuju jenjang pimpinan akan melalui hal yang mudah atau hal sulit (Gruenberg, 2011).

Isu gender di bidang teknik elektro adalah hal yang relatifbaru, namun akan dapat memberikan nilai tambah atau adding value pada ilmu rekayasa. Studi gender pun sebenarnya bukan hal yang terpisah namun merupakan kewajiban tiap bagian bidang ilmu lain. Kita harus mengakui bahwa kurikulum tidakhanya dibangun berdasarkan metodologi dan proses pembelajaran, akan tetapi juga berdasarkan nilai budaya dansosial (Perspektif, 2019). Oleh karena itu, gender issue menjadi hal menarik, terkait kurikulum dan juga hal yang mempengaruhi pengambilan keputusan dalam kurikulum tersebut, yaitu parapemimpin atau pengambil keputusan, dan para pengajar/dosenyang menjalankan putusan tersebut. 
Pengamatan women leadership pada artikel ini adalah bidang engineering, tepatnya di Jurusan Teknik Elektro Universitas Brawijaya, yang berisi observasi, dengan dukungan data terkait alumni dan pengajar/dosen. Tujuan observasi adalah mengenali isu gender khususnya di kalangan dosen teknik elektro, apakah merupakan hal utama yang perlu dicermati dan apakah perlu dicari solusinya yang terbaik. Manfaat dari observasi ini adalah mendeskripsikan kendala dan menemukan solusi untuk menunjang karier women in engineering leadership. Studi kasus ini merupakan satu pengamatan, yang pada luarannnya akan berujung untuk menjawab pertanyaan mengapa studi gender dilaksanakan di tingkat pendidikan tinggi (higher education)? belum jelas menyatakan gender para responden darikuessioner tersebut, apakah setara atau tidak.

Observasi tersebut belum memberikan gambaran gender issue di tingkat universitas. Bagaimana dengan profil JurusanTeknik Elektro Universitas Brawijaya? Untuk data klasifikasi lulusan program sarjana ataupun magister, umumnyaberdasarkan kelompok nilai IP, waktu tempuh kuliah hinggalulus, dan waktu tunggu lulusan hingga mendapat pekerjaanpertama. Jadi untuk mahasiswa atau lulusan tidak dikelompokkan berdasarkan gender. Perbandingan antara persentasi jumlah lulusan sarjana pria (mahasiswa) maupunwanita (mahasiswi) tidak atau belum dianggap penting padamasa itu. Hal ini tidak terlepas dari pernyataan bahwa sistem pembelajaran yang ada dianggap telah sesuai untuk semua gender.

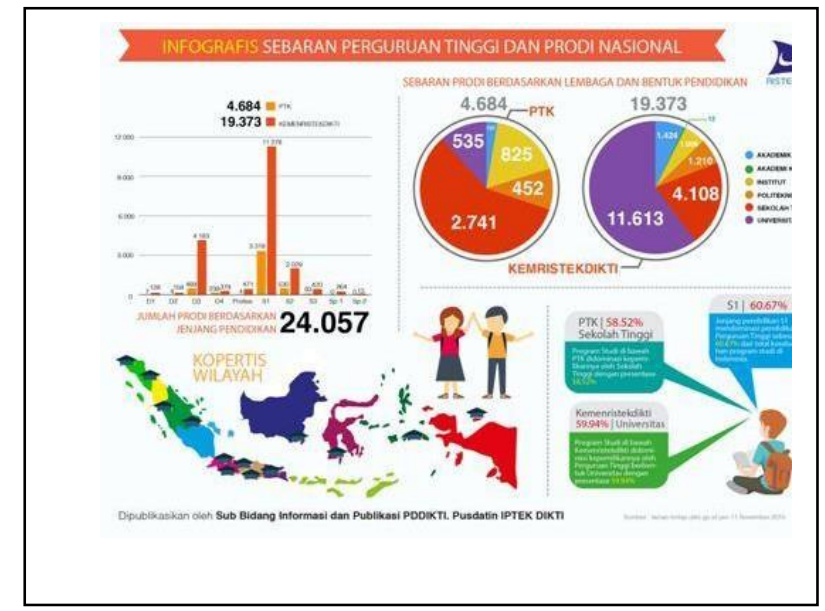

Gambar 1. Sebaran perguruan tinggi dan prodi nasional Sumber: (Widyatama, 2016)

Demikian pula untuk profil dosen/pengajar, tidak dikelompokkan berdasarkan gender, hanya berdasarkan usia, kualifikasi jabatan, jenjang pendidikan dan asal perguruan tinggi. Hal tersebut memberikan implikasi bahwa isu genderpun belum menjadi fokus bahasan pada evaluasi performansi pengajar/dosen.

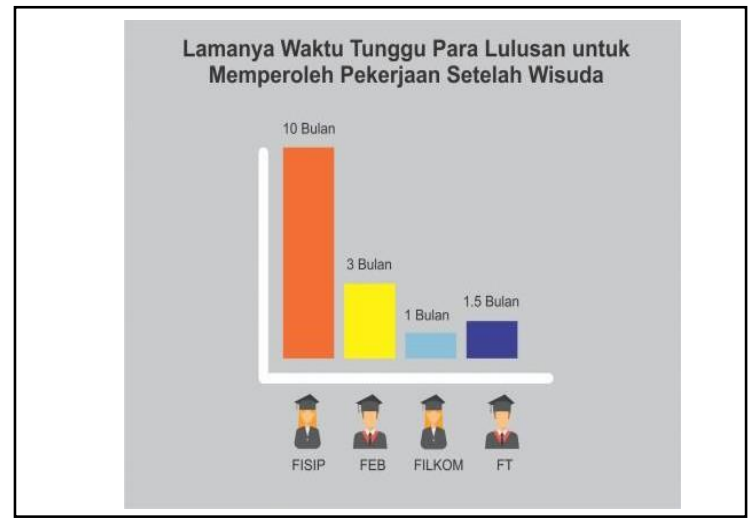

Gambar 2. Lama waktu tunggu lulusan setelah wisuda Sumber: (Perspektif, 2019)

Sebelum pengamatan khusus untuk profil dosen di teknikelektro, secara umum informasi terkait 
dosen di Indonesia diberikan oleh pusat pangkalan data perguruan tinggi; karena perguruan tinggi (PT) dan prodi nasional berada di bawahkementrian riset, teknologi dan pendidikan tinggi. Gambar 1 memberikan ilustrasi sebaran PT dan prodi tingkat nasional.Informasi terkait profil seorang dosen dapat dicari di situspangkalan data tersebut, yang selanjutnya akan dapat memberikan gambaran kesetaraan gender pada institusi tertentu, juga dapat memberikan dasar pertimbangan bagi pemegang kebijakan PT.

Selain situs tersebut, ulasan terkait lulusan atau alumni beberapa fakultas di Universitas Brawijaya (Perspektif, 2019) memberikan informasi bahwa waktu tunggu alumni setelah wisuda hinggamendapatkan pekerjaan cukup beragam (Gambar 2). Apakahini cukup explisit menunjukkan kompetensi lulusan? Tidak cukup, karena belum dibandingkan dengan point lain sepertiindex prestasi (IP) lulusan ataupun tingkat mahasiswa drop-out.

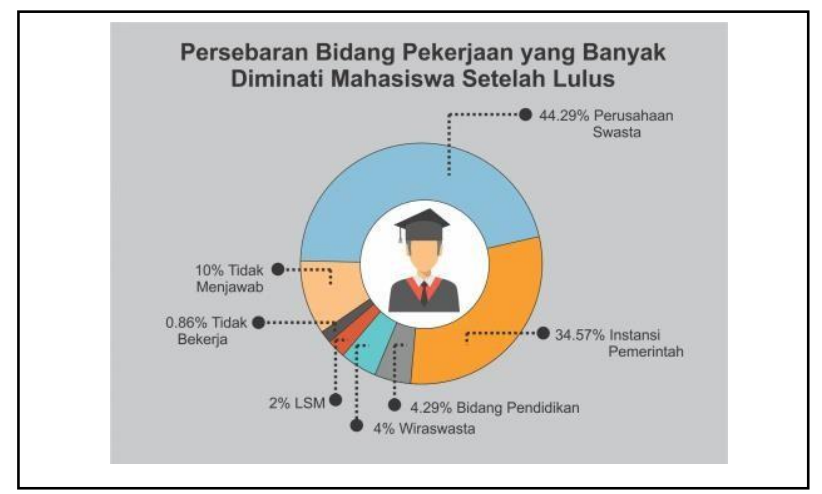

Gambar 3. Bidang minat pekerjaan setelah lulus wisuda Sumber: (Perspektif, 2019)

\section{HASIL \& DISKUSI}

Dengan mengacu pada kondisi tersebut, pada bagian diskusi berikut ini, penulis menyampaikan pembahasan terkait profil dosen pengampu mata kuliah di Jurusan TeknikElektro. Untuk dosen berjenjang pendidikan S3 hanyalah 35\%dari jumlah dosen keseluruhan, yaitu sekitar 45-59 dosen _ jumlah dalam range disebabkan ada dosen yang pension dan/atau baru aktif setelah lulus S2/S3, dimana 30\% dari angkatersebut adalah dosen wanita. Hal yang kemudian lebih jauh secara implisit menyatakan bahwa only one third of the lecturers memiliki probabilitas besar untuk menjadi "pemegang kekuasaan" di jurusan. Dari jumlah 35\% tersebut, hanya 10 dosen lulusan luarnegeri, dimana 40\% adalah dosen wanita Gambar 4. Angka put per jurusan. Apakah bidang kerja yang diminati oleh lulusan menjadi kendala penyebab lamanya waktu tunggu? Hal ini pun belum terbukti korelasinya. Informasi pada Gambar 3menunjukkan variasi minat lulusan, akan tetapi informasi ini sangat menggembirakan, sebab secara signifikan menunjukkan bahwa peluang dosen wanita menjadi pimpinancukup besar. Angka itu pun menyatakan bahwa isu gender, jika ada, tidak mengurangi langkah keberhasilan mereka untuk meraih sukses bahkan ke luar negeri, dalam hal ini besar puladukungan dari keluarga dan lingkungan kerja. Impactselanjutnya, lulusan perguruan tinggi luar negeri tentu memberikan peluang besar bagi jurusan, untuk melakukan kerjasama intenasional dengan universitas di luar negeri, seperti joint research and publication, staff and student exchange (inbound and outbound) dan program kuliah tamu dari luar negeri. 


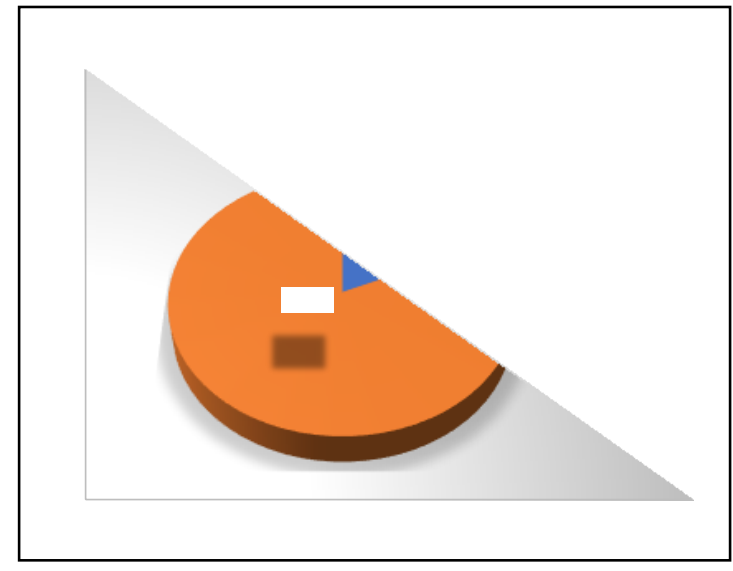

Gambar 5. Dosen Jurusan Teknik Elektro *( klasifikasi gender).

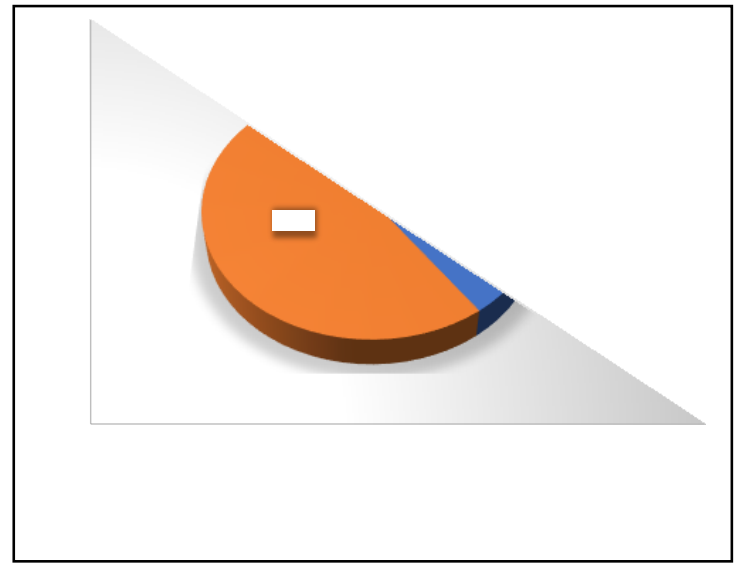

Gambar 4. Dosen Jurusan Teknik Elektro UB lulusan S3 luar negeri *( klasifikasi gender).

Secara keseluruhan memang $86 \%$ dosen telah memilikikualifikasi professional, meskipun jika melihat grafik pada Gambar 5 jumlah dosen wanita hanya 18\% dari total jumlahdosen di Jurusan Teknik Elektro. Dari fenomena ini, tentutidak membuat para wanita peminat bidang engineering berkecil hati, terutama setelah mmbaca ulasan di atas. Meskipun jumlah dosen wanita kurang dari $20 \%$ akan tetapi mereka memiliki peluang besar menjadi pimpinan atau pengambil kebijakan di jurusan. Sejak 2019 di jurusan TeknikElektro beberapa posisi pimpinan telah diisi oleh dosen wanita, seperti ketua laboratorium (misal sistem kontrol, dasar elektrik dan pengukuran), ketua peminatan atau konsentrasi studi (misal telekomunikasi, sistem energi), ketua program studi sarjana, bahkan sekretaris jurusan. Tahun 2020juga mereka mulai mengisi posisi strategis lainnya. Diskusi inipada akhirnya mengantarkan penulis pada pernyataan bahwa $90 \%$ dari angka yang kurang dari $20 \%$ tersebut, memiliki kemampuan untuk menjadi leaders di jurusan, artinya ada probabilitas besar pergeseran kepemimpinan.

Isu gender tampaknya bukanlah sebuah masalah utama khususnya di jurusan Teknik Elektro dengan bermunculannyadosen wanita sebagai leaders. Akan tetapi, untuk menjaga agarkesinambungan terjadi, maka pengenalan studi gender, misalkan untuk mata kuliah dasar umum ataupun pemberiancontoh terkait pada mata kuliah lainnya, tetap perlu dilakukan.Dosen wanita yang menjadi leaders tentu perlu mengikuti workshop untuk gender-aware, atau lebih mengenal gender diversity, atau women-leaderships' program, sehinggaselanjutnya isu gender dapat diintegrasikan tidak hanya dalam proses mengajar (gender-sensitive teaching) namun jugauntuk riset dan inovasi (Valve, 2020), (Thege,2020), (Schmeck, 2020).

\section{KESIMPULAN}

Hasil diskusi di atas menunjukkan kemungkinan adanya the shift in leaderships' role, atau pergeseran pada pola kepemimpinan. Hal mana yang kemungkinan besar dipengaruhi oleh para dosen wanita, khususnya di jurusan Teknik Elektro, yang mulai mengisi posisi-posisi strategis pengambil keputusan di level jurusan. Apakah hal itu merupakan indikasi baik? Mampukah women as leaders mengambil putusan secara objektif? Apakah para wanita, baik dosen tenaga pendidikan maupun mahasiswi, akanmendapatkan hak lebih istimewa di lingkungan kerja yang didominasi oleh para pria? Tentu akan muncul beberapa pertanyaan, akan tetapi di sini penulis ingin menekankan bahwa wanita bekerja di lingkup teknik elektro akan memiliki lingkungan kerja yang lebih kondusif, atau women friendly, apabila beberapa pengambil kebijakan/keputusan adalahwanita. 


\section{DAFTAR PUSTAKA}

McCullough, L., "Women's leadership in science, technology, engineering \& mathematics: Barriers to participation". Forum on public policy.

Gruenberg, L., "From gender studies to gender IN studies and beyond". Studies on Higher Education. UNESCO-CEPES. 2011. pp.7- 15.

Widyatama, B. (2016). "Data dosen dan informasi lainnya terpusat di PPDIKTI". https:/www.duniadosen.com/data-dosen-di-pddikti-b16/ DUNIADOSEN.com.

Perspektif. "Permasalahan lulusan UB setelah wisuda". LPM Perspektif. https://lpmperspektif.com/2019/05/23/permasalahan-lulusan-ub- setelah-wisuda/ Mei 2019.

Valve, H., (2020). "GenderWave: A digitool to support incorporation of gender perspectives into marine research and innovation”. Baltic Gender online conference. June 2020. unpublished.

Thege, B (2020) . "Gender-sensitive teaching". Baltic Gender online conference. June 2020. unpublished.

Schmeck, M. (2020)., “Setting up a women's capacity development \& leadership program.” FH Kiel; presented in Gender Seminar- Women Leaderships' Role. Collaboration UMY-UKI. Maret 2020. unpublished. 